\title{
Epidemiology and microbiology of fracture-related infection: a multicenter study in Northeast China
}

\author{
Baisheng Wang ${ }^{1,2}{ }^{\mathbb{D}}$, Xiaoguang Xiao ${ }^{3}$, Jingdong Zhang ${ }^{4}$, Wenfeng $\mathrm{Han}^{5}$, Salad Abdirahman Hersi ${ }^{1,2}$ and \\ Xin Tang ${ }^{1,2^{*}}$
}

\begin{abstract}
Objective: This study aimed to explore the epidemiological and microbiological characteristics of fracture-related infection (FRI), analyze the drug resistance characteristics of major pathogens, and provide timely and relatively complete clinical and microbiological data for antimicrobial treatment of FRI.

Methods: The clinical and microbiological data of patients with FRI from January 1, 2011, to December 31, 2020, were collected from three tertiary hospitals in Northeast China. The automatic microbial analysis system was used for strain identification and drug susceptibility testing, and the drug susceptibility results were determined in accordance with the latest Clinical and Laboratory Standards Institute (CLSI) criteria (as applicable each year).

Results: A total of 744 patients with FRI were enrolled. The incidence of FRI was about $1.5 \%$, and $81.7 \%$ were male patients, with an average age of $48.98 \pm 16.01$ years. Open fractures accounted for $64.8 \%$. Motor crush (32.8\%) and falling (29.8\%) were the main causes of injuries. The common sites of infection were the tibia and fibula (47.6\%), femur $(11.8 \%)$, foot (11.8\%), and hand (11.6\%). A total of 566 pathogenic bacteria were cultured in 378 patients with positive bacterial cultures, of which $53.0 \%$ were Gram-positive bacteria and $47.0 \%$ were Gram-negative bacteria. The most common pathogen at all sites of infection is Staphylococcus aureus. Staphylococcus aureus had a high resistance rate to penicillin (PEN), erythromycin (ERY), and clindamycin (CLI), exceeding 50\%. Methicillin-resistant Staphylococcus aureus (MRSA) was more than $80 \%$ resistant to CLI and ERY.

Conclusions: The incidence of FRI in Northeast China was at a low level among major medical centers nationwide. Staphylococcus aureus was still the main pathogen causing bone infections, and the proportion of MRSA was lower than reported abroad, but we have observed an increase in the proportion of infections. Enterobacteriaceae have a higher resistance rate to third-generation cephalosporins and quinolones. For Enterobacteriaceae, other sensitive treatment drugs should be selected clinically.
\end{abstract}

Keywords: Epidemiology, Microbiology, Fracture-related infection, Bacterial resistance

*Correspondence: surgeontangxin@hotmail.com

1 Department of Orthopedics, First Affiliated Hospital of Dalian Medical University, Dalian, Liaoning 116011, People's Republic of China

Full list of author information is available at the end of the article

\section{Introduction}

In recent years, with the rapid development of China's economy, the number of patients with open injury and multiple fractures caused by road and industrial accidents has increased dramatically [1]. Open and multiple injuries often cause infection. Infection is one of the common serious complications in orthopedics. original author(s) and the source, provide a link to the Creative Commons licence, and indicate if changes were made. The images or other third party material in this article are included in the article's Creative Commons licence, unless indicated otherwise in a credit line to the material. If material is not included in the article's Creative Commons licence and your intended use is not permitted by statutory regulation or exceeds the permitted use, you will need to obtain permission directly from the copyright holder. To view a copy of this licence, visit http://creativecommons.org/licenses/by/4.0/. The Creative Commons Public Domain Dedication waiver (http://creativeco mmons.org/publicdomain/zero/1.0/) applies to the data made available in this article, unless otherwise stated in a credit line to the data. 
Long treatment cycles, high treatment costs, and poor prognosis bring huge physical and mental harm to patients, as well as huge challenges to doctors and healthcare systems. The total medical cost of infected patients after tibial fracture is 6.5 times that of uninfected patients, antibiotic treatment time is 11 times that of uninfected patients, and the hospital stay is 7.7 times that of uninfected patients [2]. The risk of fracture-related infection (FRI) depends on the location of the injury, severity, and the accompanying injury and physiological state of the host. The incidence of infection after closed low-energy fractures is about $1 \%$, and the incidence of infection after complex open fractures is about $15 \%$ [3, 4]. FRI is usually caused by exogenous factors such as initial trauma or surgery [5].

The clinical features of FRI are diverse and may be affected by geographic location, climate, time, and injury factors [6-8]. The epidemiological and microbiological characteristics of patients with FRI are particularly important for guiding clinical treatment. The current lack of epidemiological and microbiological research reports on FRI. To solve this problem, we retrospectively analyzed 744 patients with FRI from 2011 to 2020 in three large tertiary hospitals in Northeast China. This study explores the epidemiological and microbiological characteristics of patients with FRI and analyzes the characteristics of drug-resistant bacteria spectrum of main pathogens. This study can provide evidence-based medicine for the empirical treatment of FRI with antibiotics.

\section{Methods}

This study reviewed the medical records of patients hospitalized for fractures from January 1, 2011, to December 31,2020, and selected cases of patients with FRI that met the inclusion criteria, including gender, age, injury factors, infection site, comorbidities, bacterial culture, and drug sensitivity test results. The diagnostic criteria for FRI referred to the diagnostic criteria by the Association for the Study of Internal Fixation (AO/ASIF) [9]. Microscan WalkAway 96 plus (Beckman, USA) or VITEK 2 Compact (Meyer, France) automatic microbial analysis system is used for strain identification and antimicrobial susceptibility testing. The results of antimicrobial susceptibility testing were determined in accordance with the latest CLSI criteria (as applicable each year). The minimum inhibitory concentrations (MICs) were used to detect methicillinresistant $S$. aureus. Quality control strains include $S$. aureus (ATCC 25923), E. coli (ATCC25922), and P. aeruginosa (ATCC27853) (National Health Commission Clinical Laboratory Center).

\section{Inclusion criteria}

1. Patient eligible for diagnosis of FRI

\section{Exclusion criteria}

1. Incomplete medical record

2. Multi-site infection

3. Pathological fracture such as bone tuberculosis and bone tumor

4. Periprosthetic infection

5. Infections of the skull, sternum, and ribs

\section{Diagnostic criteria for FRI}

The diagnostic criteria of FRI are divided into confirmatory criteria (the present infection can be determined as long as a confirmatory criterion is met) and suggestive criteria (features of FRI that related to infection but need to be further investigated). There are four confirmatory criteria: (1) fistula, sinus, or wound breakdown (with communication to the bone or the implant); (2) purulent drainage from the wound or the presence of pus during surgery; (3) phenotypically indistinguishable pathogens identified by culture from at least two separate deep tissue/implant specimens taken during an operative intervention; and (4) presence of microorganisms in deep tissue taken during an operative intervention, as confirmed by histopathological examination using specific staining techniques for bacteria or fungi. Suggestive diagnosis criteria include clinical signs, inflammatory signs, radiological signs, new-onset joint effusion, persistent wound drainage, and pathogenic organism culture results. The detailed diagnostic criteria of FRI refer to the consensus by the Association for the Study of Internal Fixation (AO/ASIF) [9].

\section{Ethics approval and informed consent}

The collected data was anonymized and de-identified before data analysis. The Institutional Review Board of First Affiliated Hospital of Dalian Medical University granted a waiver of written informed consent and provided authorization for this study (number PJ-KSKY-2021-31). The study protocol was registered with the Chinese Clinical Trial Registry. All related procedures were performed in accordance with relevant guidelines and regulations.

\section{Statistics analysis}

Statistical analysis was performed with the SPSS 22.0 software (SPSS Inc., Chicago, IL, USA). Application of WHONET 5.6 software was performed for 
bacterial resistance analysis. Statistics was described as mean \pm standard deviation (SD) or as the count and percentage as appropriate. A chi-square test or KruskalWallis $H$ test was used to analyze the difference in count data. All the significance tests were two-sided tests, and $P<0.05$ was considered statistically significant.

\section{Results}

According to the inclusion and exclusion criteria, 744 patients with FRI from 2011 to 2020 were screened out from 48,186 fracture patients who were treated surgically in our centers. The incidence of FRI was about $1.5 \%$, of which $378(50.8 \%)$ patients had positive bacterial cultures. The study included 608 males (81.7\%) and 136 females (18.3\%) with an average age of $48.98 \pm 16.01$ years. The most patients were 50 to 59 (216 cases, 29.03\%). Four hundred fifty-two (60.8\%) patients came from the outpatient department, and 292 (39.2\%) patients came from the emergency department. There were $482(64.8 \%)$ open fractures and 504 (67.7\%) single fractures. One hundred twelve (15.1\%) patients had neurovascular injury, $68(9.1 \%)$ patients had diabetes, and 70 (9.4\%) patients had hypertension (Table 1 and Fig. 1). The largest number of patients was in the third quarter, $33.9 \%$ of the year (Fig. 2). The most common causes of injuries were motor crush (244 cases, $32.8 \%$ ) and falling (222 cases, 29.8\%) (Fig. 3). There were 142 (19.1\%) cases of upper extremity bone infection and $556(74.7 \%)$ of lower extremity bone infection, and the common sites of infection were the tibia and fibula (354 cases, $47.6 \%$ ), femur ( 88 cases, $11.8 \%$ ), foot ( 88 cases, $11.8 \%$ ), and hand (86 cases, $11.6 \%$ ) (Fig. 4).

A total of 566 pathogenic bacteria were cultured from 378 patients with positive bacterial culture, including 300 (53.0\%) Gram-positive bacteria and 266 (47.0\%) Gram-negative bacteria. The common pathogens are Staphylococcus aureus (166 strains, 29.3\%), Staphylococcus epidermidis (44 strains, 7.8\%), Pseudomonas aeruginosa (42 strains, 7.4\%), Escherichia coli (40 strains, 7.1\%), Klebsiella pneumoniae (36 strains, 6.4\%), and Enterobacter cloacae (28 strains, 4.9\%). MRSA in 2020 (12 strains, 37.5\%) increased compared with 2011 (4 strains, $14.3 \%)$, but the difference was not statistically significant $(P>0.05)$ (Table 2).

Among the 378 patients with positive bacterial culture, $268(70.9 \%)$ were infected by a single pathogen and 110 (29.1\%) were infected by multiple pathogens. Among the patients with single pathogen infection, there were 198 (73.9\%) strains of Gram-positive bacteria and 70 (26.1\%) strains of Gram-negative bacteria. The main Gram-positive bacteria were $S$. aureus $(128,64.6 \%)$ and $S$. epidermidis $(28,14.1 \%)$. The main Gram-negative bacteria were P. aeruginosa (16 strains, 22.9\%), E. cloacae (12, 17.1\%), and E. coli (8 strains, 11.4\%). Among the patients with multiple infections, 102 (34.2\%) were Gram-positive bacteria and 196 (65.8\%) were Gram-negative bacteria. The main Gram-positive bacteria were $S$. aureus (40, 39.2\%) and S. epidermidis (16, 15.7\%). The main Gram-negative bacteria were $E$. coli (32, 16.3\%), P. aeruginosa (32, $16.3 \%$ ), and K. pneumoniae (26, 13.3\%). S. aureus was the most common pathogenic bacteria in all infection sites, and the hand and forearm had a higher infection rate of Gram-negative bacteria (Figs. 5 and 6).

S. aureus had high resistance rates to penicillin (PEN), erythromycin (ERY), and clindamycin (CLI), all exceeding $50 \%$. MRSA was completely resistant to PEN, oxacillin (OXA), amoxicillin/clavulanic acid (AMC), and ceftriaxone (CRO). The resistance rate of MRSA to CLI and ERY was more than $80 \%$. The resistance rate of S. epidermidis to PEN, OXA, AMC, CRO, and ERY was more than $80 \%$ (Tables 3 and 4). The resistance rate of E. coli to ampicillin (AMP), cefazolin (CZO), and cefuroxime (CXM) was more than $70 \%$, and it was completely sensitive to carbapenemases such as imipenem (IPM), meropenem (MEM), and ertapenem (ETP). The resistance rate of $K$. pneumoniae to ampicillin (ATM), ciprofloxacin (CIP), CZO, CXM, CRO, and compound sulfamethoxazole (SXT) was more than $50 \%$. The resistance rate of $P$. aeruginosa to commonly used drugs was less than $30 \%$ (Table 5).

\section{Discussion}

FRI is one of the most daunting and challenging complications in the treatment of trauma patients, which can lead to delayed healing, permanent loss of function, and even amputation [10,11]. FRI can also cause huge socio-economic cost and lead to a significantly prolonged recovery period for patients. Antibiotics play an important role in the prevention and treatment of FRI [12]. The treatment of FRI is complicated and requires a standardized, long-term antibiotic treatment regimen [13]. Clarifying the clinical characteristics and dominant pathogenic strains of current FRI is of great significance for guiding clinical treatment. There have been no reports of epidemiological studies on FRI in Northeast China, in order to clarify the epidemiological and microbiological characteristics of FRI in Northeast China to guide the use of clinical empirical antibiotics. We conducted a retrospective study on patients with FRI from 2011 to 2020 in three tertiary hospitals in Northeast China.

The incidence of FRI in our research centers for 10 years is $1.5 \%$, which is at a low level compared to other research $(0.4$ to $16.1 \%)$ [14]. This may be related to our strict screening criteria. First of all, previous studies mostly used SSI defined by the CDC as the diagnostic criteria of infection [15-20]. Compared with the 
Table 1 Demographic characteristics of 744 patients with fracture-related infection (2011-2020)

\begin{tabular}{|c|c|c|c|c|c|c|}
\hline & 2011-2012 & 2013-2014 & 2015-2016 & 2017-2018 & 2019-2020 & Total \\
\hline $\mathrm{Age}^{\mathrm{a}}$ & $47 \pm 16$ & $49 \pm 17$ & $50 \pm 15$ & $50 \pm 16$ & $48 \pm 15$ & $49 \pm 16$ \\
\hline Male/female & $104 / 22$ & $112 / 20$ & $146 / 26$ & $140 / 32$ & $106 / 36$ & $608 / 136$ \\
\hline \multicolumn{7}{|l|}{$\operatorname{Admission}(n[\%])$} \\
\hline Outpatient & $78(62)$ & $86(65)$ & $112(65)$ & $104(60)$ & $72(51)$ & $452(61)$ \\
\hline Emergency & $48(38)$ & $46(35)$ & $60(35)$ & $68(40)$ & $70(49)$ & $292(39)$ \\
\hline \multicolumn{7}{|l|}{ Fracture type ( $n$ [\%]) } \\
\hline Single fracture & $88(70)$ & $86(65)$ & $118(69)$ & $118(69)$ & $94(66)$ & $504(68)$ \\
\hline Multiple fracture & $38(30)$ & $46(35)$ & $54(31)$ & $54(31)$ & $48(34)$ & $240(32)$ \\
\hline \multicolumn{7}{|l|}{ Wound type (n [\%]) } \\
\hline Open injury & $84(67)$ & $96(73)$ & $108(63)$ & $110(64)$ & $84(59)$ & $482(65)$ \\
\hline Closed injury & $42(33)$ & $36(27)$ & $64(37)$ & $62(36)$ & $58(41)$ & $262(35)$ \\
\hline \multicolumn{7}{|l|}{ Infection site ( $n[\%])$} \\
\hline Upper limb & $16(13)$ & $26(21)$ & $34(20)$ & $46(27)$ & $20(14)$ & $142(19)$ \\
\hline Lower limb & $100(79)$ & $104(78)$ & $122(71)$ & $116(67)$ & $114(80)$ & $556(75)$ \\
\hline Vertebrae and sacrococcyx & $10(8)$ & $2(1)$ & $16(9)$ & $10(6)$ & $8(6)$ & $46(6)$ \\
\hline \multicolumn{7}{|l|}{ Side ( $n[\%])$} \\
\hline Left & $66(52)$ & $66(50)$ & $78(45)$ & $80(47)$ & $70(49)$ & $360(48)$ \\
\hline Axis & $10(8)$ & $2(2)$ & $18(10)$ & $8(5)$ & $12(8)$ & $50(7)$ \\
\hline Right & $50(40)$ & $64(49)$ & $76(44)$ & $84(49)$ & $60(42)$ & $334(45)$ \\
\hline \multicolumn{7}{|l|}{ Injury mechanism (n [\%]) } \\
\hline Motor crush & $38(30)$ & $50(38)$ & $62(36)$ & $44(26)$ & $50(35)$ & $244(33)$ \\
\hline Falling & $38(30)$ & $42(32)$ & $52(30)$ & $56(33)$ & $34(24)$ & $222(30)$ \\
\hline Fall from height & $14(11)$ & $8(6)$ & $14(8)$ & $8(5)$ & $10(7)$ & $54(7)$ \\
\hline Bruise & $12(10)$ & $6(5)$ & $14(8)$ & $18(10)$ & $12(8)$ & $62(8)$ \\
\hline Cutting & $12(10)$ & $16(12)$ & $22(13)$ & $26(15)$ & $12(8)$ & $88(12)$ \\
\hline Others & $12(10)$ & $10(8)$ & $8(5)$ & $20(12)$ & $24(17)$ & $74(10)$ \\
\hline \multicolumn{7}{|l|}{ Complication (n [\%]) } \\
\hline Diabetes & $12(10)$ & $10(8)$ & $12(7)$ & $26(15)$ & $8(6)$ & $68(9)$ \\
\hline Hypertension & $4(3)$ & $8(6)$ & $22(13)$ & $28(16)$ & $8(6)$ & $70(9)$ \\
\hline Neurovascular injury & $26(21)$ & $16(12)$ & $20(12)$ & $34(20)$ & $16(11)$ & $112(15)$ \\
\hline Compartment syndrome & $4(3)$ & $2(2)$ & $6(3)$ & $6(3)$ & $2(1)$ & $20(3)$ \\
\hline Cardiovascular disease & $4(3)$ & $0(0)$ & $10(6)$ & $8(5)$ & $2(1)$ & $24(3)$ \\
\hline Shock & $10(8)$ & $4(3)$ & $10(6)$ & $8(5)$ & $14(10)$ & $46(6)$ \\
\hline Chest and abdomen injuries & $4(3)$ & $6(5)$ & $8(5)$ & $10(6)$ & $6(4)$ & $34(5)$ \\
\hline Brain injury & $2(2)$ & $6(5)$ & $8(5)$ & $4(2)$ & $0(0)$ & $20(3)$ \\
\hline
\end{tabular}

${ }^{a}$ The values are given as the mean and the standard deviation

diagnostic criteria of SSI, the diagnostic criteria recommended by FRI consensus are more detailed, which exclude the patients with superficial SSI infection [9]. Secondly, previous studies have mostly focused on a specific part. These parts have a high risk of postoperative infection, such as the tibia, ankle joint, and calcaneus $[16,17,21,22]$. Finally, due to the large number of variables in the clinical and microbial characteristics of the patients, we excluded medical records with missing data. These may be the reason why the incidence rate of infection in our study is lower than other studies. The third quarter is a period of high incidence of FRI, and there is a significant time difference in the risk of infection. The mechanism is not clear, and related studies speculate that the risk of infection may be related to climate, temperature, and humidity [23, 24]. Motor crush is the most common cause of injury (32.8\%), which is inseparable from the rapid development of traffic development in China. Among patients with FRI, men accounted for approximately $81.8 \%$, which is similar to the Kremers report [8]. The report believes that men are more likely to engage in heavy manual labor or high-risk activities, 
玉 Male $\equiv$ Female

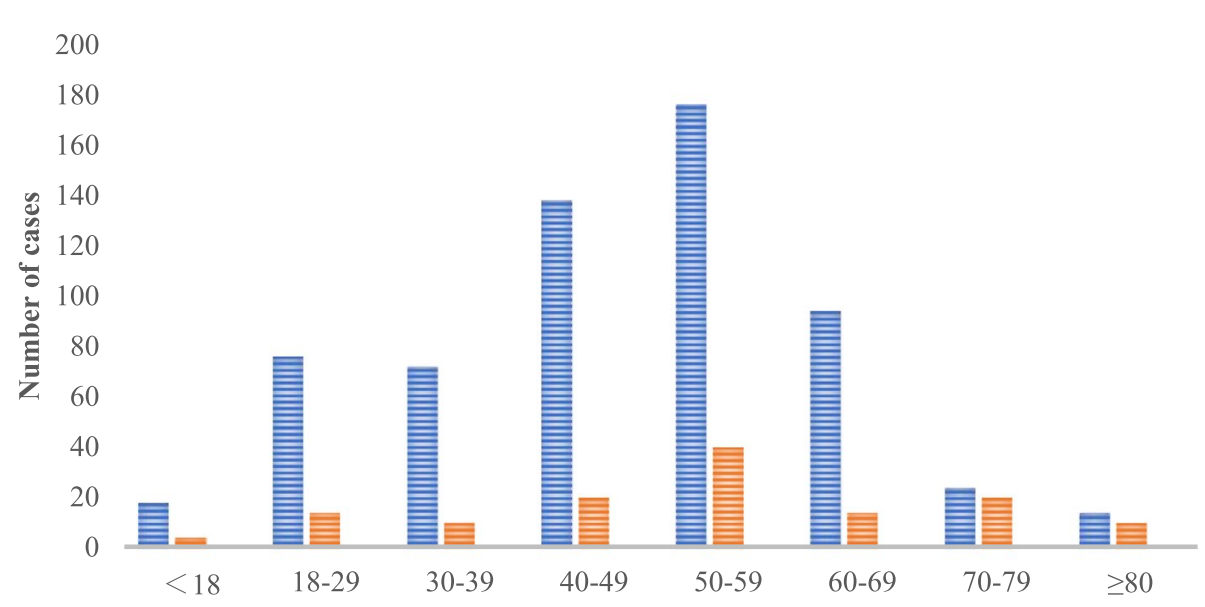

Fig. 1 Distribution of age and gender

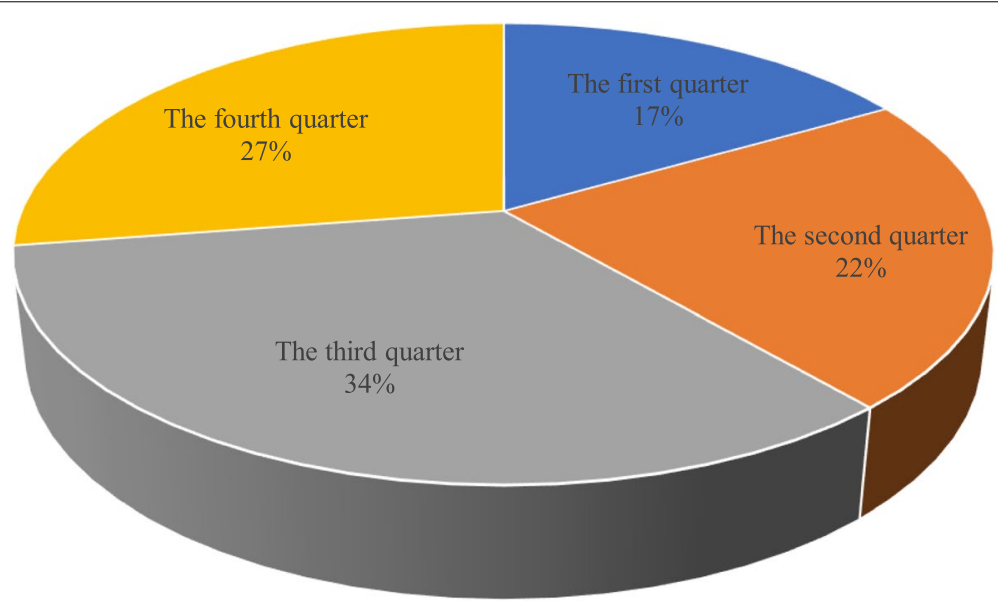

Fig. 2 Seasonal distribution of cases

and the increase in road and industrial accidents has led to more male patients. In this study, the 50-59 years old accounted for the highest proportion, probably because this age group is engaged in high-risk operations, which may easily lead to fractures, and this part of the population often has diseases that increase the risk of infection, such as diabetes [25]. Diabetes is a common complication of FRI in this study. Immunity is an important factor in the occurrence and transformation of osteomyelitis [26]. Older people have weaker immunity and probably more prone to infection [27]. The most common infection sites were the tibia and fibula (47.6\%), femur (11.8\%), foot bone (11.8\%), and hand bone (11.6\%), which is similar to related reports [28, 29]. There is less soft tissue around the tibia, and the lack of blood supply after trauma or surgery increases the chance of wound infection.
Bacterial culture results showed Gram-positive bacteria $(53.0 \%)$ and Gram-negative bacteria (47.0\%). As expected, S. aureus $(29.3 \%)$ is the most common pathogenic bacteria, of which $25.3 \%$ are MRSA. Gram-negative bacteria are mainly $P$. aeruginosa $(7.4 \%)$, E. coli (7.1\%), and K. pneumoniae (6.4\%), which are similar to related research [7, 30]. Enterobacteriaceae accounted for $29.3 \%$ in this study, which is similar to a recent study that reported that $35.5 \%$ of bone infections were related to Enterobacteriaceae. The higher incidence of Enterobacteriaceae infection may be related to the fact that most of these patients suffered open fracture after direct trauma, and/or infection caused by soft tissue injury [28]. P. aeruginosa is common in our study, accounting for $12.8 \%$, which is quite worrying because $P$. aeruginosa has been found to be associated with an increased 


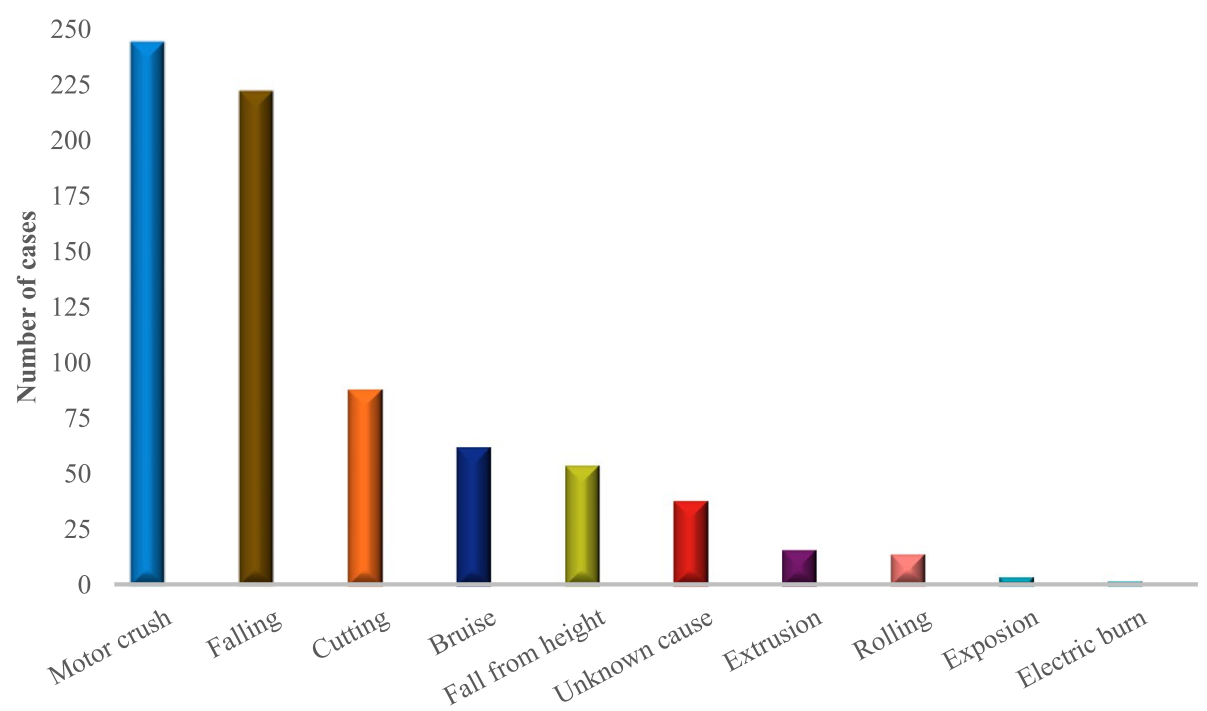

Fig. 3 Distribution of injury mechanism

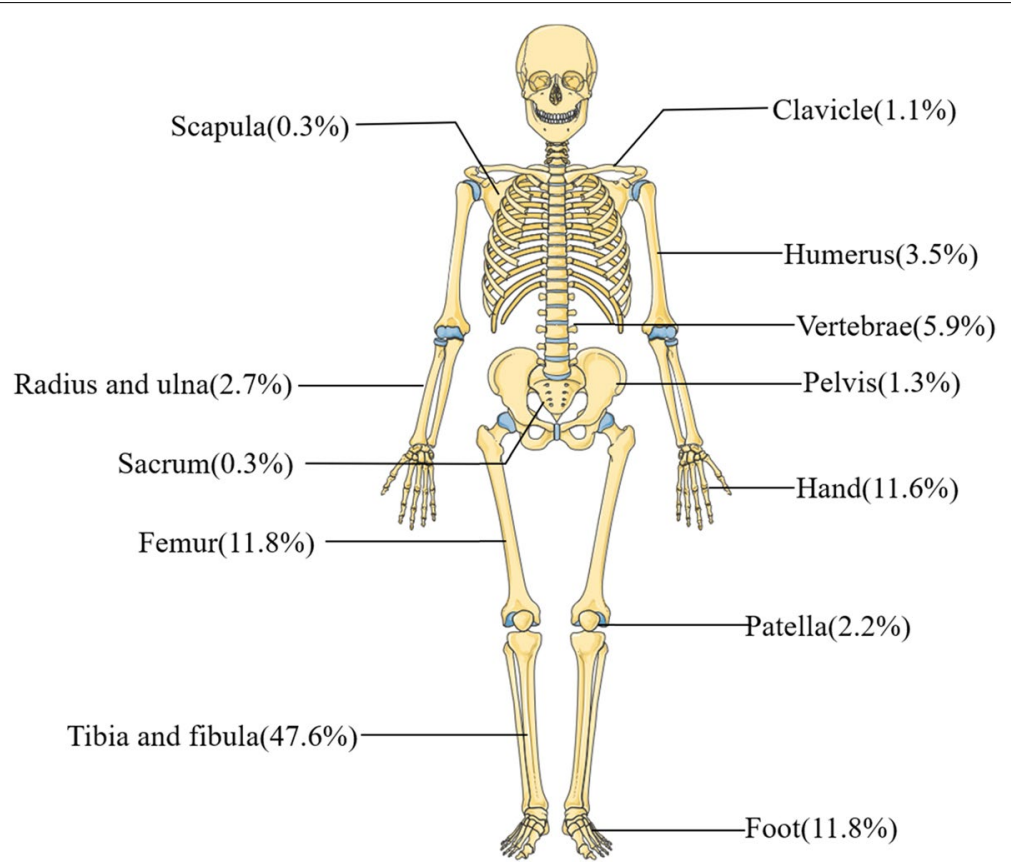

Fig. 4 Distribution of infection sites

risk of recurrence of osteomyelitis [31, 32]. 25.3\% of $S$. aureus are resistant to oxacillin in our study, which is lower than reports in Brazil (35.5\%) and the Middle East $(60.5 \%)[32,33]$. This may be related to more cautious use of antibiotics and more strict control of nosocomial infection in these centers. We recommend that if FRI is suspected, antibiotics should not be used before surgical debridement unless the patient has sepsis [34]. During the operation, sterile instruments were used to collect multiple tissue samples for microbiological and histopathological examinations. If signs of FRI (e.g., pus) are found during surgery, empirical intravenous antibacterial therapy should be started immediately after sampling. The empirical antimicrobial treatment should be continued until the microbiological results are available, and then reassessment. Our empirical antibiotic strategy 
Table 2 Main pathogens of FRI (2011-2020)

\begin{tabular}{|c|c|c|c|c|c|c|}
\hline & 2011-2012 & 2013-2014 & $2015-2016$ & $2017-2018$ & $2019-2020$ & Total \\
\hline SAU & 28 & 34 & 36 & 36 & 32 & 166 \\
\hline MSSA & 24 & 28 & 26 & 26 & 20 & 124 \\
\hline$M_{R S A}{ }^{a}$ & 4 & 6 & 10 & 10 & 12 & 42 \\
\hline SEP & 16 & 2 & 10 & 8 & 8 & 44 \\
\hline PAE & 8 & 10 & 8 & 14 & 2 & 42 \\
\hline ECO & 12 & 2 & 6 & 12 & 8 & 40 \\
\hline KPN & 6 & 0 & 6 & 16 & 8 & 36 \\
\hline Total & 70 & 48 & 66 & 86 & 58 & 328 \\
\hline
\end{tabular}

${ }^{a}$ Comparison between the proportion of MRSA in 2019-2020 and 2011-2012, $P>0.05$

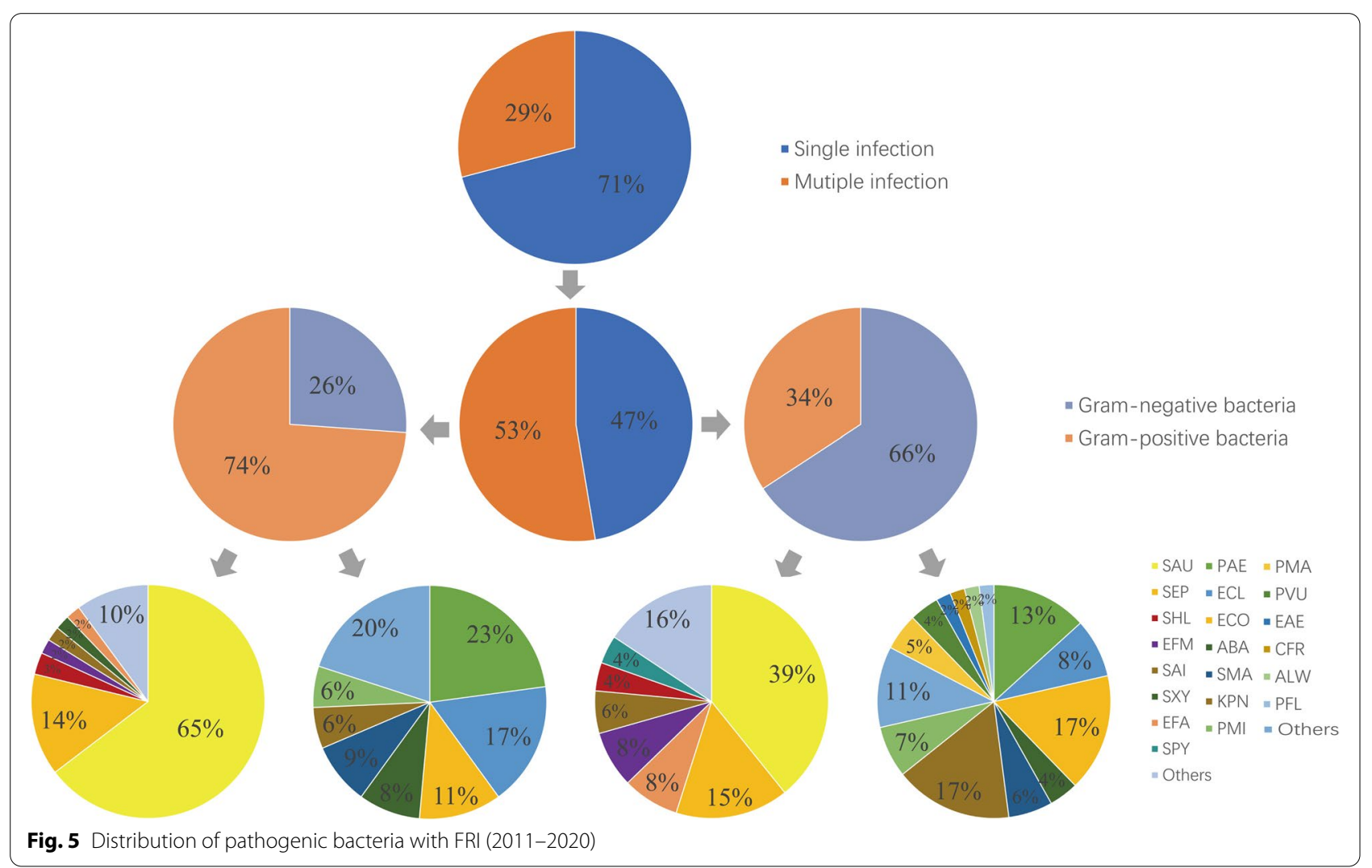

is third-generation cephalosporin combined with vancomycin and then adjusted according to the culture results [13]. The resistance rate of $S$. aureus to rifampicin and fluoroquinolone is less than $20 \%$, and it is recommended as the first-line oral treatment for Staphylococcus [35]. When $S$. aureus is resistant to oxacillin, intravenous vancomycin is recommended first. Coagulase-negative Staphylococcus (e.g., S. epidermidis) is resistant to oxacillin, which is consistent with the treatment strategy for MRSA. Enterobacteriaceae have a high resistance rate to third-generation cephalosporins, and we speculate that their resistance is usually related to the production of extended-spectrum $\beta$-lactamase (ESBLs) [36]. However, this study lacks relevant experimental data and cannot determine its resistance mechanism. Fluoroquinolone is the cornerstone for the treatment of bone and joint infections caused by Gram-negative bacteria [37]. But the resistance rate of Enterobacteriaceae to fluoroquinolones in this study is higher than $50 \%$. According to the results of the Enterobacteriaceae susceptibility test in our study, we recommend the use of carbapenem antibiotics (e.g., meropenem and imipenem). Although P. aeruginosa has a high sensitivity to fluoroquinolones in this study, we do not recommend fluoroquinolones as the initial 


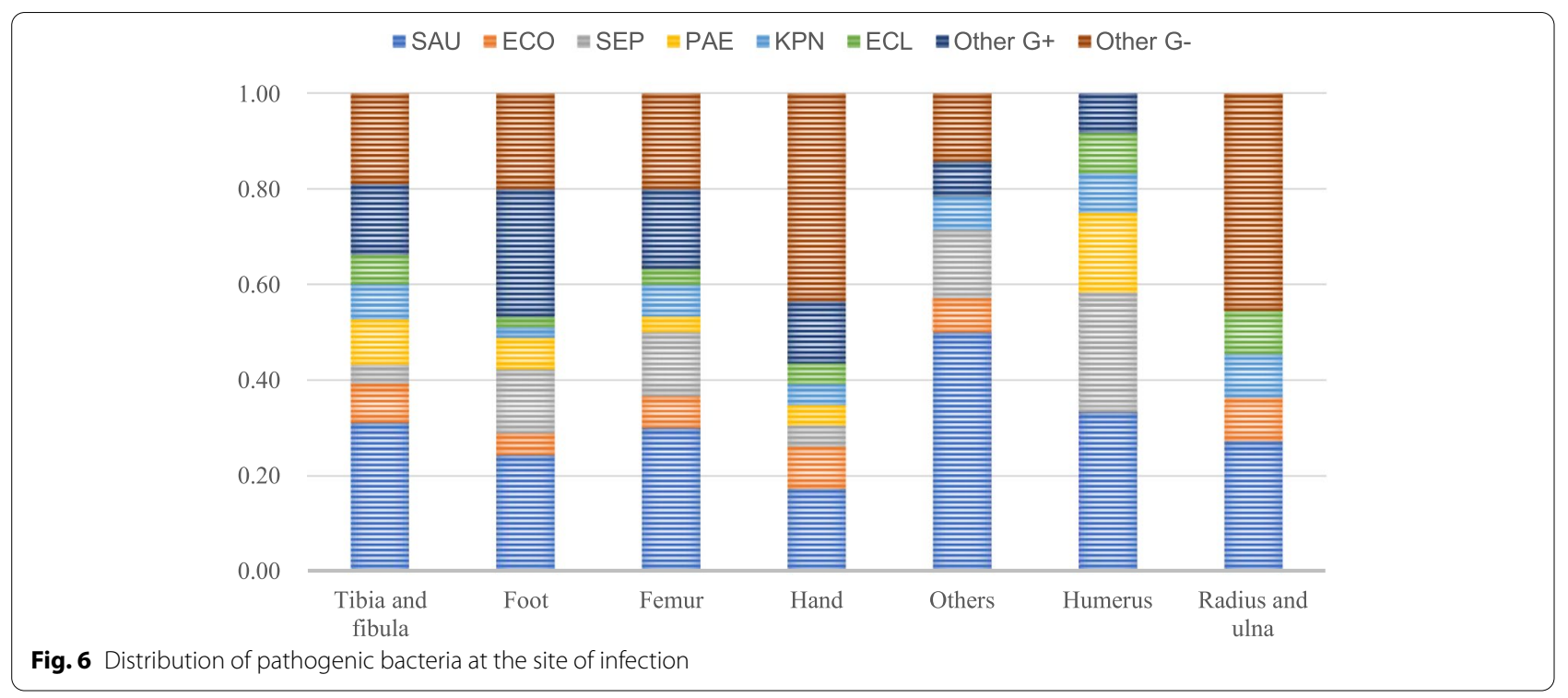

Table 3 Antimicrobial resistance of the main Gram-positive bacteria

\begin{tabular}{|c|c|c|c|c|c|c|}
\hline \multirow[t]{2}{*}{ Antimicrobial } & \multicolumn{3}{|c|}{ S. aureus $(n=166)$} & \multicolumn{3}{|c|}{ S. epidermidis $(n=44)$} \\
\hline & $R(\%)$ & $I(\%)$ & $S(\%)$ & $R(\%)$ & $I(\%)$ & $S(\%)$ \\
\hline PEN & 96.4 & 0 & 3.6 & 100.0 & 0 & 0 \\
\hline OXA & 25.3 & 0 & 74.7 & 81.8 & 0 & 18.2 \\
\hline AMC & 25.3 & 0 & 74.7 & 86.4 & 0 & 13.6 \\
\hline CRO & 25.3 & 0 & 74.7 & 86.4 & 0 & 13.6 \\
\hline GEN & 24.1 & 1.2 & 74.7 & 36.4 & 4.5 & 59.1 \\
\hline RIF & 3.6 & 0 & 96.4 & 13.6 & 0 & 86.4 \\
\hline CIP & 15.7 & 18.1 & 66.3 & 59.1 & 0 & 40.9 \\
\hline LVX & 14.5 & 1.2 & 84.3 & 59.1 & 0 & 40.9 \\
\hline MFX & 14.5 & 1.2 & 84.3 & 40.9 & 18.2 & 40.9 \\
\hline SXT & 4.8 & 0 & 95.2 & 40.9 & 0 & 59.1 \\
\hline $\mathrm{CLI}$ & 51.8 & 2.4 & 45.8 & 59.1 & 0 & 40.9 \\
\hline DAP & 0 & 0 & 100.0 & 0 & 0 & 100.0 \\
\hline ERY & 69.9 & 2.4 & 27.7 & 81.8 & 0 & 18.2 \\
\hline LNZ & 0 & 0 & 100.0 & 0 & 0 & 100.0 \\
\hline VAN & 0 & 0 & 100.0 & 0 & 0 & 100.0 \\
\hline QDA & 3.6 & 0 & 96.4 & 4.5 & 0 & 95.5 \\
\hline TCY & 15.7 & 3.6 & 80.7 & 22.7 & 4.5 & 72.7 \\
\hline
\end{tabular}

treatment after debridement because they may have a higher resistance rate. We recommend third-generation cephalosporins or carbapenems as the initial treatment for non-fermenting bacteria (e.g., P. aeruginosa) [13]. Carbapenem-resistant strains are rare in this study. However, due to the global spread of carbapenemase-resistant Enterobacteriaceae bacteria since 2012, it is expected that the resistance will increase in the future, requiring to be paid more attention by clinicians [38].
This study includes several limitations. This is a retrospective study with a relatively small sample size. We did not keep fresh samples for complete gene sequencing to understand gene mutations and protein expression levels. China has a vast territory; ethnic groups, climates, living customs, and eating habits of different regions are diverse. Our results only represent cases of FRI in this region. The types of antibiotics selected by medical institutions in different periods are different. Although 
Table 4 Antimicrobial resistance of MRSA and MSSA

\begin{tabular}{|c|c|c|c|c|c|c|}
\hline \multirow[t]{2}{*}{ Antimicrobial } & \multicolumn{3}{|c|}{ MRSA $(n=42)$} & \multicolumn{3}{|c|}{$\operatorname{MSSA}(n=124)$} \\
\hline & $R(\%)$ & $I(\%)$ & $S(\%)$ & $R(\%)$ & $I(\%)$ & $S(\%)$ \\
\hline PEN & 100.0 & 0 & 0 & 95.2 & 0 & 4.8 \\
\hline OXA & 100.0 & 0 & 0 & 0 & 0 & 100.0 \\
\hline AMC & 100.0 & 0 & 0 & 0 & 0 & 100.0 \\
\hline CRO & 100.0 & 0 & 0 & 0 & 00 & 100.0 \\
\hline GEN & 33.3 & 4.8 & 61.9 & 21.0 & 0 & 79.0 \\
\hline RIF & 14.3 & 0 & 85.7 & 0 & 0 & 100.0 \\
\hline CIP & 19.0 & 9.5 & 71.4 & 14.5 & 21.0 & 64.5 \\
\hline LVX & 19.0 & 4.8 & 76.2 & 12.9 & 0 & 87.1 \\
\hline MFX & 19.0 & 0 & 81.0 & 12.9 & 1.6 & 85.5 \\
\hline SXT & 14.3 & 0 & 85.7 & 1.6 & 0 & 98.4 \\
\hline $\mathrm{CLI}$ & 81.0 & 0 & 19.0 & 41.9 & 3.2 & 54.9 \\
\hline DAP & 0 & 0 & 100.0 & 0 & 0 & 100.0 \\
\hline ERY & 85.7 & 4.8 & 9.5 & 64.5 & 1.6 & 33.9 \\
\hline LNZ & 0 & 0 & 100.0 & 0 & 0 & 100.0 \\
\hline VAN & 0 & 0 & 100.0 & 0 & 0 & 100.0 \\
\hline QDA & 14.3 & 0 & 85.7 & 0 & 0 & 100.0 \\
\hline TCY & 38.1 & 4.8 & 57.1 & 8.1 & 3.2 & 88.7 \\
\hline
\end{tabular}

Table 5 Antimicrobial resistance of the main Gram-negative bacteria

\begin{tabular}{|c|c|c|c|c|c|c|c|c|c|}
\hline \multirow[t]{2}{*}{ Antimicrobial } & \multicolumn{3}{|c|}{ E. coli $(n=40)$} & \multicolumn{3}{|c|}{ K. pneumoniae $(n=36)$} & \multicolumn{3}{|c|}{ P. aeruginosa $(n=42)$} \\
\hline & $R(\%)$ & $I(\%)$ & $S(\%)$ & $R(\%)$ & $I(\%)$ & $S(\%)$ & $R(\%)$ & $I(\%)$ & $S(\%)$ \\
\hline CSL & 20.0 & 15.0 & 65.0 & 16.7 & 16.7 & 66.6 & 4.8 & 23.8 & 71.4 \\
\hline TZP & 15.0 & 5.0 & 80.0 & 16.7 & 5.6 & 77.8 & 9.5 & 9.5 & 81.0 \\
\hline CAZ & 45.0 & 5.0 & 50.0 & 33.3 & 16.7 & 50.0 & 9.5 & 9.5 & 81.0 \\
\hline FEP & 50.0 & 0 & 50.0 & 44.4 & 5.6 & 50 & 14.3 & 4.8 & 80.9 \\
\hline ATM & 50.0 & 0 & 50.0 & 61.1 & 0 & 38.9 & 23.8 & 14.3 & 61.9 \\
\hline IPM & 0 & 0 & 100.0 & 16.7 & 0 & 83.3 & 9.5 & 0 & 90.5 \\
\hline MEM & 0 & 0 & 100.0 & 16.7 & 0 & 83.3 & 9.5 & 0 & 90.5 \\
\hline AMK & 15.0 & 5.0 & 80.0 & 5.6 & 0 & 94.4 & 0 & 9.5 & 90.5 \\
\hline GEN & 55.0 & 0 & 45.0 & 22.2 & 5.6 & 72.2 & 14.3 & 0 & 85.7 \\
\hline TOB & 40.0 & 15.0 & 45.0 & 27.8 & 16.7 & 55.6 & 9.5 & 0 & 90.5 \\
\hline CIP & 65.0 & 0 & 35.0 & 50.0 & 0 & 50.0 & 0 & 9.5 & 90.5 \\
\hline LVX & 55.0 & 5.0 & 40.0 & 38.9 & 11.1 & 50.0 & 0 & 9.5 & 90.5 \\
\hline AMP & 95.0 & 0 & 5.0 & 100.0 & 0 & 0 & - & - & - \\
\hline CZO & 75.0 & 0 & 25.0 & 55.6 & 0 & 44.4 & - & - & - \\
\hline CXM & 65.0 & 5.0 & 30.0 & 55.6 & 0 & 44.4 & - & - & - \\
\hline CRO & 60.0 & 0 & 40.0 & 55.6 & 0 & 44.4 & - & - & - \\
\hline FOX & 25.0 & 5.0 & 70.0 & 38.9 & 0 & 61.1 & - & - & - \\
\hline ETP & 0 & 0 & 100.0 & 16.7 & 0 & 83.3 & - & - & - \\
\hline SXT & 65.0 & 0 & 35.0 & 55.6 & 0 & 44.4 & - & - & - \\
\hline
\end{tabular}

we have selected as many commonly used antibiotics as possible in the research design to obtain the results of bacterial drug sensitivity tests, it still cannot fully reflect the actual situation. Our research included the period of the Sars-COVID-19 pandemic, and we do not know any 
influences on the epidemiology of FRI yet. So, it would be a known bias.

\section{Conclusion}

The incidence of FRI in our centers was at a low level in large medical centers across the country. Staphylococcus aureus was still the main pathogen causing bone infections. The proportion of MRSA was still lower than reported abroad, but we have observed an increase in the proportion of infections. Enterobacteriaceae had higher resistance rates to third-generation cephalosporins and fluoroquinolones. Other sensitive treatment drugs should be selected clinically for Enterobacteriaceae. This study showed the epidemiological, clinical, and microbiological characteristics of FRI in three centers. These results can provide a basis for formulating effective preventive measures and treatment plans and reduce the burden of treatment of FRI.

\begin{abstract}
Abbreviations
FRI: Fracture-related infection; CLSI: Clinical and Laboratory Standards Institute; MRSA: Methicillin-resistant Staphylococcus aureus; ESBL: Extended-spectrum $\beta$-lactamase; AO/ASIF: Association for the Study of Internal Fixation; MICs: Minimum inhibitory concentrations.
\end{abstract}

\section{Acknowledgements}

We would like to thank Xiaoguang Xiao for his assistance in the data collection and statistics process.

\section{Authors' contributions}

BW and XT conceived this idea, develop the proposal, perform the analysis, and prepared the manuscript. BW, JZ, and WH collected the data. SAH polished the language of the article. All authors have read and approved this final manuscript.

\section{Funding}

None.

\section{Availability of data and materials}

All data generated or analyzed during this study are included in this published article.

\section{Declarations}

\section{Ethics approval and consent to participate}

The collected data was anonymized and de-identified before data analysis. The Institutional Review Board of First Affiliated Hospital of Dalian Medical University granted a waiver of written informed consent and provided authorization for this study (number PJ-KS-KY-2021-31).

\section{Consent for publication}

Not applicable.

\section{Competing interests}

The authors declare that they have no competing interests.

\section{Author details}

${ }^{1}$ Department of Orthopedics, First Affiliated Hospital of Dalian Medical University, Dalian, Liaoning 116011, People's Republic of China. ${ }^{2}$ Dalian Medical University, Dalian, Liaoning 116044, People's Republic of China. ${ }^{3}$ Department of Clinical Laboratory, First Affiliated Hospital of Dalian Medical University, Dalian, Liaoning 116011, People's Republic of China. ${ }^{4}$ Department of Orthopedics, Northeast International Hospital, Shenyang, Liaoning 110004 ,
People's Republic of China. ${ }^{5}$ Department of Orthopedics, The General Hospital of Northern Theater Command, Shenyang, Liaoning 110016, People's Republic of China.

Received: 26 April 2021 Accepted: 24 July 2021

Published online: 12 August 2021

\section{References}

1. Wang S, Li Y, Chi G, Xiao S, Ozanne-Smith J, Stevenson M, Phillips M. Injury-related fatalities in China: an under-recognised public-health problem. Lancet (London, England). 2008;372(9651):1765-73.

2. Metsemakers W-J, Smeets B, Nijs S, Hoekstra H. Infection after fracture fixation of the tibia: analysis of healthcare utilization and related costs. Injury. 2017;48(6):1204-10.

3. Papakostidis C, Kanakaris NK, Pretel J, Faour O, Giannoudis PV. Prevalence of complications of open tibial shaft fractures stratified as per the GustiloAnderson classification. Injury. 2011;42(12):1408-15.

4. Cook GE, Markel DC, Ren W, Webb LX, Mckee MD, Schemitsch EH. Infection in orthopaedics. J Orthop Trauma. 2015;29:S19-23.

5. Trampuz A, Zimmerli W. Diagnosis and treatment of infections associated with fracture-fixation devices. Injury. 2006;37(Suppl 2(2)):S59-66.

6. Jiang N, Ma YF, Jiang Y, Zhao XQ, Yu B. Clinical characteristics and treatment of extremity chronic osteomyelitis in Southern China: a retrospective analysis of 394 consecutive patients. Medicine. 2015;94(42):e1874.

7. Wang X, Yu S, Sun D, Fu J, Wang S, Huang K, Xie Z. Current data on extremities chronic osteomyelitis in southwest China: epidemiology, microbiology and therapeutic consequences. Sci Rep. 2017;7(1):16251.

8. Kremers HM, Nwojo ME, Ransom JE, Wood-Wentz CM, Melton LJ 3rd, Huddleston PM 3rd. Trends in the epidemiology of osteomyelitis: a population-based study, 1969 to 2009. J Bone Joint Surg Am. 2015;97(10):837-45.

9. Metsemakers WJ, Morgenstern M, McNally MA, Moriarty TF, McFadyen I, Scarborough M, Athanasou NA, Ochsner PE, Kuehl R, Raschke M, et al. Fracture-related infection: a consensus on definition from an international expert group. Injury. 2018;49(3):505-10.

10. Darouiche RO. Treatment of infections associated with surgical implants. N Engl J Med. 2004;172(5):2102-2102.

11. Basilico M, Vitiello R, Oliva MS, Covino M, Greco T, Cianni L, Dughiero G, Ziranu A, Perisano C, Maccauro G. Predictable risk factors for infections in proximal femur fractures. J Biol Regul Homeost Agents. 2020;34(3 Suppl. 2):77-81.

12. Ziranu A, Lillo M, Fantoni M, Maffulli N, Maccauro G. Single dose cefazolin is safe and effective for pre-operative prophylaxis in orthopaedic oncology. J Biol Regul Homeost Agents. 2018:32(6 Suppl. 1):45-9.

13. Depypere M, Kuehl R, Metsemakers WJ, Senneville E, McNally MA, Obremskey WT, Zimmerli W, Atkins BL, Trampuz A, Fracture-Related Infection Consensus $\mathrm{G}$. Recommendations for systemic antimicrobial therapy in fracture-related infection: a consensus from an international expert group. J Orthop Trauma. 2020;34(1):30-41.

14. Zimmerli W. Clinical presentation and treatment of orthopaedic implantassociated infection. J Intern Med. 2014;276(2):111-9.

15. Solomkin JS, Mazuski J, Blanchard JC, Itani KMF, Ricks P, Dellinger EP, Allen G, Kelz R, Reinke CE, Berríos-Torres SI. Introduction to the Centers for Disease Control and Prevention and the Healthcare Infection Control Practices Advisory Committee guideline for the prevention of surgical site infections. Surg Infect (Larchmt). 2017;18(4):385-93.

16. Wang $\mathrm{H}$, Pei $\mathrm{H}$, Chen $\mathrm{M}$, Wang $\mathrm{H}$. Incidence and predictors of surgical site infection after ORIF in calcaneus fractures, a retrospective cohort study. J Orthop Surg Res. 2018;13(1):293.

17. Sun R, Li M, Wang X, Li X, Wu L, Chen Z, Chen K. Surgical site infection following open reduction and internal fixation of a closed ankle fractures: a retrospective multicenter cohort study. Int J Surg. 2017;48:86-91.

18. Liang Z, Rong K, Gu W, Yu X, Fang R, Deng Y, Lu L. Surgical site infection following elective orthopaedic surgeries in geriatric patients: incidence and associated risk factors. Int Wound J. 2019;16(3):773-80.

19. Zhao K, Zhang J, Li J, Meng H, Wang Z, Zhu Y, Hou Z, Zhang Y. Incidence and risk factors of surgical site infection after intertrochanteric fracture surgery: a prospective cohort study. Int Wound J. 2020;17(6):1871-80. 
20. Lu K, Zhang J, Cheng J, Liu H, Yang C, Yin L, Wang H, You X, Qu Q. Incidence and risk factors for surgical site infection after open reduction and internal fixation of intra-articular fractures of distal femur: a multicentre study. Int Wound J. 2019;16(2):473-8.

21. Li J, Zhu Y, Zhao K, Zhang J, Meng H, Jin Z, Ma J, Zhang Y. Incidence and risks for surgical site infection after closed tibial plateau fractures in adults treated by open reduction and internal fixation: a prospective study. J Orthop Surg Res. 2020;15(1):349.

22. Greco T, Vitiello R, Cazzato G, Cianni L, Malerba G, Maccauro G, Perisano C. Intramedullary antibiotic coated nail in tibial fracture: a systematic review. J Biol Regul Homeost Agents. 2020;34(3 Suppl. 2):63-9.

23. Anthony CA, Peterson RA, Polgreen LA, Sewell DK, Polgreen PM. The seasonal variability in surgical site infections and the association with warmer weather: a population-based investigation. Infect Control Hosp Epidemiol. 2017;38(7):809-16.

24. Sagi HC, Donohue D, Cooper S, Barei DP, Siebler J, Archdeacon MT, Sciadini M, Romeo M, Bergin PF, Higgins T. Institutional and seasonal variations in the incidence and causative organisms for posttraumatic infection following open fractures. J Orthop Trauma. 2017;31(2):78-84.

25. Vitiello R, Perisano C, Covino M, Perna A, Bianchi A, Oliva MS, Greco T, Sirgiovanni M, Maccauro G. Euthyroid sick syndrome in hip fractures: valuation of vitamin D and parathyroid hormone axis. Injury. 2020;51(Suppl 3):S13-s16.

26. Pincher B, Fenton C, Jeyapalan R, Barlow G, Sharma HK. A systematic review of the single-stage treatment of chronic osteomyelitis. J Orthop Surg Res. 2019;14(1):393.

27. Cierny Gl, Mader JT, Penninck JJ. The classic: a clinical staging system for adult osteomyelitis. Clin Orthop Relat Res. 2003;414(414):7-24.

28. Peng J, Ren Y, He W, Li Z, Xu Y. Epidemiological, clinical and microbiological characteristics of patients with post-traumatic osteomyelitis of limb fractures in Southwest China: a hospital-based study. J Bone Jt Infect. 2017;2(3):149-53.

29. Zhang X, Lu Q, Liu T, Li Z, Cai W. Bacterial resistance trends among intraoperative bone culture of chronic osteomyelitis in an affiliated hospital of South China for twelve years. BMC Infect Dis. 2019;19(1):823.

30. Ma X, Han S, Ma J, Chen X, Bai W, Yan W, Wang K. Epidemiology, microbiology and therapeutic consequences of chronic osteomyelitis in northern China: a retrospective analysis of 255 patients. Sci Rep. 2018;8(1):14895.
31. Chadayammuri V, Herbert B, Hao J, Mavrogenis A, Quispe JC, Kim JW, Young $\mathrm{H}$, Hake M, Mauffrey C. Factors associated with adverse postoperative outcomes in patients with long bone post-traumatic osteomyelitis. Eur J Orthop Surg Traumatol. 2017;27(7):877-82.

32. Jorge LS, Chueire AG, Fucuta PS. Predisposing factors for recurrence of chronic posttraumatic osteomyelitis: a retrospective observational cohort study from a tertiary referral center in Brazil. Patient Saf Surg. 2017;11(1):1-9.

33. Fily F, Ronat JB, Malou N, Kanapathipillai R, Seguin C, Hussein N, Fakhri RM, Langendorf C. Post-traumatic osteomyelitis in Middle East war-wounded civilians: resistance to first-line antibiotics in selected bacteria over the decade 2006-2016. BMC Infect Dis. 2019;19(1):1-8.

34. Singer M, Deutschman CS, Seymour CW, Shankar-Hari M, Annane D, Bauer M, Bellomo R, Bernard GR, Chiche JD, Coopersmith CM, et al. The third international consensus definitions for sepsis and septic shock (Sepsis-3). JAMA. 2016;315(8):801-10.

35. Osmon DR, Berbari EF, Berendt AR, Lew D, Zimmerli W. Diagnosis and management of prosthetic joint infection: clinical practice guidelines by the Infectious Diseases Society of America. Clin Infect Dis. 2013;56(1):1-10.

36. Roer L, Hansen F, Thomsen MCFL, Knudsen JD, Hansen DSD, Wang M, Samulioniené J, Justesen US, Røder BL, Schumacher H. WGS-based surveillance of third-generation cephalosporin-resistant Escherichia coli from bloodstream infections in Denmark. J Antimicrob Chemother. 2017;72(7):1922-9.

37. Rodríguez-Pardo D, Pigrau C, Lora-Tamayo J, Soriano A, del Toro MD, Cobo J, Palomino J, Euba G, Riera M, Sánchez-Somolinos M, et al. Gram-negative prosthetic joint infection: outcome of a debridement, antibiotics and implant retention approach. A large multicentre study. Clin Microbiol Infect. 2014;20(11):0911-919.

38. Logan LK, Weinstein RA. The epidemiology of carbapenem-resistant Enterobacteriaceae: the impact and evolution of a global menace. J Infect Dis. 2017;215(suppl_1):S28.

\section{Publisher's Note}

Springer Nature remains neutral with regard to jurisdictional claims in published maps and institutional affiliations.
Ready to submit your research? Choose BMC and benefit from:

- fast, convenient online submission

- thorough peer review by experienced researchers in your field

- rapid publication on acceptance

- support for research data, including large and complex data types

- gold Open Access which fosters wider collaboration and increased citations

- maximum visibility for your research: over $100 \mathrm{M}$ website views per year

At BMC, research is always in progress.

Learn more biomedcentral.com/submissions 